\title{
Optimalisasi Desain Struktur Bogie Las Light Rail Transit (LRT) Menggunakan Perhitungan Finite Element Method (FEM)
}

\author{
Mustasyar Perkasa $^{1,2, *}$ dan Wahyu Sulistiyo ${ }^{1}$

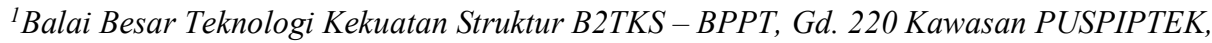 \\ Tangerang Selatan, Indonesia \\ ${ }_{2}^{2}$ Program Studi Teknik Mesin, Universitas Pamulang, Jl. Surya Kencana No. 1, Tangerang Selatan, Indonesia \\ E-mail: *mustasyar.perkasa@bppt.go.id
}

Masuk:18 September 2018 Direvisi :29 November 2018 Disetujui : 3 Januari 2019

\begin{abstract}
Abstrak: Dalam mendesain kereta api, perlu dilakukan beberapa tahapan pengujian terhadap kekuatan komponen dan struktur kereta api. Penggunaan bogie las sebagai komponen untuk kereta light rail transit (LRT) di lakukan untuk meningkatkan sistem keselamatan pada kereta LRT. Kegiatan penelitian ini bertujuan untuk meningkatkan faktor keamanan bogie las LRT yang telah ada. Metode yang di lakukan dalam penelitian ini adalah melakukan optimalisasi desain bogie las LRT dengan cara rekayasa geometri dan struktur rangka bogie sehingga didapatkan hasil yang terbaik dari penambahan penguatan pada bogie LRT. Dari hasil pengujian struktur bogie las LRT, struktur rangka bogie masih perlu dilakukan penguatan karena pada saat pengujian statis tegangan maksimum yang terjadi hampir mendekati tegangan luluh materialnya. Untuk itu perlu dilakukan redesain untuk bogie frame dengan rekayasa geometri dalam bentuk penguatan pada struktur framenya. Penambahan penguatan ini akan disimulasikan dengan menggunakan sofware finite element method (FEM). Sofware FEM digunakan untuk melakukan analisa kekuatan struktur bogie las LRT sehingga dipastikan desain bogie las memenuhi standar keamanan sebelum melalui proses pengujian, atau sering disebut sebagai tahap verifikasi desain yang selanjutnya desain bogie frame ini dijadikan sebagai salah satu alternatif desain.
\end{abstract}

Kata kunci: keamanan kereta api, bogie, bogie las, desain struktur, finite element method

\begin{abstract}
In designing trains, it is necessary to carry out several stages of testing the strength of railroad components and structures. The use of welding bogies as a component for light rail transit (LRT) trains is done to improve the safety system of LRT trains. This research activity aims to improve the safety factor of existing LRT bogie las. The method used in this research is to optimize the LRT welding bogie design by geometric engineering and bogie frame structure so that the best results are obtained from the addition of reinforcement to the LRT bogie. From the LRT welding bogie structure test results, the bogie frame structure still needs to be strengthened because at the time of static testing the maximum stress that occurs is almost close to the yield stress of the material. For this reason it is necessary to redesign the bogie frame with geometric engineering in the form of reinforcement in the frame structure. The addition of this reinforcement will be simulated using the finite element method (FEM) software. FEM software is used to analyze the strength of the LRT welded bogie structure so that the welded bogie design meets safety standards before going through the testing process, or often referred to as the design verification stage, then the bogie frame design is used as an alternative design.
\end{abstract}

Keywords: the safety of train, bogie, welding bogie, design of the structure, finite element method

\section{PENDAHULUAN}

Kereta api merupakan salah satu sarana transportasi massal yang cukup efisien, baik untuk pengangkutan manusia maupun barang. Melihat fungsinya yang sangat vital, karena berkaitan dengan keselamatan manusia maupun barang, maka kereta api dituntut memiliki kemampuan yang cukup memadai sehingga tidak mengalami kerusakan yang disebabkan oleh beban operasinya. Untuk memberikan kepastian kepastian terhadap kekuatan 
komponen dan struktur kereta api di lakukan beberapa tahapan pengujian. Salah satunya adalah pengujian experimental terhadap komponen maupun struktur [1].

Kereta api di bangun dari beberapa komponen dan struktur. Komponen utama yang mutlak di perlukan untuk menjamin kekuatan dan keselamatan kereta api adalah komponen bogie. Terdapat dua macam jenis bogie pada kereta api berdasarkan cara pembuatannya yaitu bogie cor dan bogie las. Bogie cor adalah jenis bogie yang umumnya di gunakan pada kereta api barang. Bogie cor terdiri dari dua komponen utama yaitu rangka samping (side frame) dan rangka melintang (bolster). Sedangkan bogie las adalah jenis bogie yang digunakan pada kereta penumpang. Pada jenis ini, bogie di buat dari bahan pelat yang di bangun menjadi struktur bogie dengan menggunakan sistem pengelasan $[2,3]$.

Selain komponen bogie, komponen atau struktur lain yang mutlak dituntut kekuatannya adalah struktur gerbong dan rangka bawah. Masalah teknologi pada produk bogie di tentukan dari hasil pengujian dimana pada beberapa titik atau lokasi terjadinya konsentrasi tegangan yang mendekati batas tegangan yang diijinkan. Dengan kata lain, walaupun desain yang telah di buat cukup aman untuk di gunakan secara operasional, namun angka faktor keamanannya perlu di tingkatkan untuk mamastikan kehandalan produk tersebut [4-9]. Penelitian yang bertujuan untuk meningkatkan faktor keamanan bukan saja menjamin keamanan transportasi namun juga dapat memenuhi tuntutan pasar global dan keselamatan penumpang yaitu dengan dihasilkannya produk bogie kereta api berdaya saing tinggi [3]. Tujuan yang ingin di capai dalam penelitian ini adalah untuk mendapatkan struktur bogie las yang optimun yang akan di gunakan sebagai bogie LRT melalui pendekatan desain dan pengujian.

\section{METODOLOGI}

Spesifikasi lokomotif yang menjadi objek penelitian adalah : Lokomotif Diesel Hidrolik dengan type CC300 dengan double cabin, memakai bogie konstruksi tiga gandar. Panjang keseluruhan $19 \mathrm{~m}$, lebar 2,790 m, berat 87 ton, beban axle 15 ton. Mesin menggunakan mesin diesel cartepillar dengan transmisi voith. Sistem pengereman menggunakan produk wabtec, master controller menggunakan produk woojin dari korea selatan. Lokomotif mempunyai power 2200 HP dengan di lengkapi generator set Caterpillar (CAT C15) yang di gunakan sebaagai sumber listrik untuk rangkaian penumpang. Dengan demikian tidak di perlukan lagi kereta khusus untuk power. Apabila lokomotif digunakan untuk menarik gerbong maka generator set dapat di matikan. Rencana operasi untuk di daerah jawa. Desain dan struktur bogie di produksi oleh perusahaan kereta api indonesia dengan kecepatan maksimum $120 \mathrm{~km} / \mathrm{jam}$ dan kecepatan operasinya $100 \mathrm{~km} / \mathrm{jam}$. Kebaruan dari bogie ini adalah mempunyai 3 gandar, sederhana dan mudah dalam perewatannya.

\section{Spesifikasi Bogie}

Massa maksimum lokomotif

Jumlah gandar

Beban maksimum gandar

Massa bogie

Massa wheel set

Lebar jalan rel

Radius jalan rel minimum

Diameter roda kereta

Jarak roda

Jarak suspensi

Kecepatan operasi maksimum

\author{
: 90 ton \\ $: 3$ \\ : 15 ton \\ : 10 ton \\ : 1,97 ton (spesifikasi voith) \\ : $1067 \mathrm{~mm}$ \\ : $150 / 80 \mathrm{~m}$ \\ : $914 \mathrm{~mm}$ \\ : $3500 \mathrm{~mm}$ \\ : $1640 \mathrm{~mm}$ \\ : $120 \mathrm{~km} / \mathrm{jam}$
}

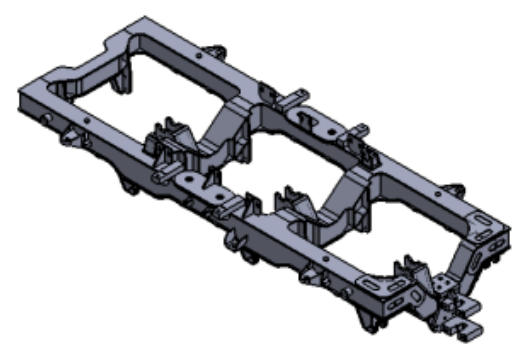

Gambar 1. Bogie las 
26 | Mustasyar Perkasa dkk., Optimalisasi Desain Struktur Bogie Las Light Rail Transit....,

\section{Data Material}

Jenis material

Modulus elastisitas

Poison ratio

Massa jenis

Tegangan yield

Tegangan tarik maksimum

Standar
: SM 400B

$: 2,1 \times 10^{5} \mathrm{MPa}$

$: 0,3$

: $7,8 \times 10^{-3} \mathrm{~kg} / \mathrm{mm}^{2}$

$: 245 \mathrm{~N} / \mathrm{mm}^{2}$

: $400 \mathrm{~N} / \mathrm{mm}^{2}$

: JIS G3106

Lingkup dan tahapan kegiatan penelitian ini mencakup proses iteratif dari analisa dan optimalisasi desain dengan beberapa simulasi alternatif dengan mengambil referensi hasil pengujian statis dan dinamis yang pernah di lakukan pada bogie generasi pertama. Untuk melaksanakan kegiatan ini di gunakan perangkat lunak ANSYS dan fasilitas pengujian yang ada di Balai Besar Teknologi Kekuatan Struktur (B2TKS - BPPT). Adapun besarnya beban uji berdasarkan standar UIC 515 seperti pada Tabel 1.

Tabel 1. Simulasi pembebanan bogie [3]

\begin{tabular}{|c|c|c|c|c|c|c|c|c|c|c|c|c|c|}
\hline \multirow{2}{*}{ Kasus Beban } & \multirow{2}{*}{$\begin{array}{c}\text { Vertikal } \\
\text { Fy }\end{array}$} & \multicolumn{2}{|c|}{ Lateral } & \multicolumn{2}{|c|}{ Longitudinal } & \multicolumn{2}{|c|}{ Brake Set } & \multicolumn{2}{|c|}{ Gear Box } & \multicolumn{2}{|c|}{ Traction Load } & \multirow{2}{*}{$\begin{array}{c}\text { Twist } \\
G\end{array}$} & \multirow{2}{*}{$\mathrm{Uji}$} \\
\hline & & Fzsd & Fzst & Fxc & Fxb & Fxs & Fys & Fxg & Fzg & Fxt & Fyt & & \\
\hline 1 & $\mathrm{v}$ & - & - & - & - & - & - & \multicolumn{2}{|c|}{-} & \multicolumn{2}{|c|}{-} & - & \\
\hline 2 & $\mathrm{~V}$ & - & - & - & - & - & - & \multicolumn{2}{|c|}{-} & \multicolumn{2}{|c|}{ - } & $\mathrm{v}$ & \\
\hline 3 & $\mathrm{v}$ & $\mathrm{v}$ & $\mathrm{v}$ & - & - & - & - & \multicolumn{2}{|c|}{-} & \multicolumn{2}{|c|}{-} & $\mathrm{v}$ & \\
\hline 4 & $\mathrm{v}$ & - & - & $\mathrm{V}$ & - & - & - & \multicolumn{2}{|c|}{-} & \multicolumn{2}{|c|}{-} & - & \\
\hline 5 & $\mathrm{v}$ & $\mathrm{v}$ & $\mathrm{v}$ & - & - & - & - & \multicolumn{2}{|c|}{$\mathrm{v}$} & \multicolumn{2}{|c|}{-} & - & \\
\hline 6 & $\mathrm{v}$ & $\mathrm{v}$ & $\mathrm{v}$ & $\mathrm{V}$ & - & - & - & \multicolumn{2}{|c|}{-} & \multirow{2}{*}{\multicolumn{2}{|c|}{ - }} & - & \\
\hline 7 & $\mathrm{v}$ & $\mathrm{v}$ & $\mathrm{v}$ & & $\mathrm{v}$ & $\mathrm{v}$ & $\mathrm{v}$ & \multicolumn{2}{|c|}{$\mathrm{v}$} & & & - & \\
\hline 8 & $\mathrm{v}$ & $\mathrm{v}$ & $\mathrm{v}$ & $\mathrm{v}$ & $\mathrm{v}$ & $\mathrm{v}$ & $\mathrm{v}$ & \multicolumn{2}{|c|}{$\mathrm{V}$} & \multicolumn{2}{|c|}{$\mathrm{v}$} & - & \\
\hline Actuator & 1 & 5 & 4 & & & 3 & 2 & \multirow{2}{*}{\multicolumn{2}{|c|}{$\frac{6}{17^{\circ}}$}} & \multicolumn{2}{|c|}{7} & - & \\
\hline Sudut & 0 & 0 & 0 & 0 & 0 & 0 & 0 & & & \multicolumn{2}{|c|}{$9^{\circ}$} & - & \\
\hline Ekivalen gaya $(\mathrm{KN})$ & 450 & 28 & 40 & 310 & 143 & 303 & 07 & \multicolumn{2}{|c|}{63} & \multicolumn{2}{|c|}{75} & $17,5 \mathrm{~mm}$ & \\
\hline
\end{tabular}

\section{Kondisi Pembebanan}

Pembebanan pada bogie terdiri dari beban pada arah lateral, beban pada arah vertikal dan beban pada arah longitudinal $[2,3]$. Besarnya beban pada arah lateral yaitu

$$
F_{Z}=2 *\left[10^{4}+\frac{M v \cdot g}{12}\right]
$$

Dimana

Fz : Gaya lateral total

Mv : Massa lokomotif $\left(9 \times 10^{4} \mathrm{~kg}\right)$

$g \quad$ : Gravitasi $\left(9,81 \mathrm{~m} / \mathrm{s}^{2}\right)$

Jadi besarnya gaya lateral untuk pengujian bogie sebesar $167150 \mathrm{~N}$

Beban lateral yang di terima rangka bogie pada pegas secondary akibat displacement antara bogie dan carbody saat kondisi lintasan belok sebesar

$$
F z s p=k * \Delta z
$$

Dimana

Fzsp : Gaya lateral setiap pegas secondary

$k \quad$ : Kekakuan pegas secondary $(315 \mathrm{~N} / \mathrm{mm})$

$\Delta z \quad$ : Defleksi pegas $(60 \mathrm{~mm})$, di peroleh dari penyimpangan posisi bogie terhadap carbody saat melalui lintasan belok dengan radius $80 \mathrm{~m}$.

Jadi besarnya gaya lateral yang di terima rangka bogie pada satu pegas secondary sebesar $18909 \mathrm{~N}$.

Beban lateral yang diterima rangka bogie pada sisi luar salah satu lateral stopper sebesar 


$$
F z s t=[(F z s d-(4 * F z s p)] / 4
$$

Dimana

Fzst : Gaya lateral setiap lateral stopper pada sisi luar salah satu lateral stopper dan lateral dumper Beban vertikal dari secondary spring sebesar

$$
F y=\frac{1,3(M v-2 M b)}{n s} \cdot \mathrm{g}
$$

Dimana

Fy : Gaya vertikal pada setiap secondary spring (N) (penerapan gaya pada dudukan secondary spring)

Mv : Massa lokomotif $\left(9 \times 10^{4} \mathrm{~kg}\right)$

$\mathrm{Mb} \quad$ : Massa bogie motor $\left(1 \times 10^{4} \mathrm{~kg}\right)$

$g \quad:$ Gravitasi $\left(9,81 \mathrm{~m} / \mathrm{s}^{2}\right)$

ns : Jumlah secondary spring (8)

Jadi besarnya gaya vertikal pada secondary spring sebesar $111589 \mathrm{~N}$

\section{Pemodelan Elemen Hingga}

Pemodelan elemen hingga di lakukan dengan cara menentukan mendefinisikan sumbu pada desain bogie dan menentukan type elemen [3-9]

Sistem sumbu yang di gunakan :

$\mathrm{X}$ : Sebagai sumbu longitudinal

Y: sebagai sumbu vertikal

$\mathrm{Z}$ : sebagai sumbu lateral

Tipe elemen :

1. Sheel 4 node dengan 6 derajat kebebasan pada setiap node (sheel 63) untuk memodelkan under frame dari struktur carbody.

2. Beam 2 node dengan 6 derajat kebebasan pada setiap node (beam 4).

Untuk memodelkan rangka struktur carbody

1. Combine 14, garis yang menghubungkan 2 node dengan 3 derajat kebebasan dan memiliki karakteristik kekakuan dan redaman memodelkan pegas primer dan sekunder.

Sistem satuan

1. Mimimeter (mm) untuk jarak.

2. Newton (N) untuk beban.

3. Mega Pascal (MPa) untuk tegangan.

\section{Kondisi Batas}

Pada bidang simetri $\mathrm{X}-\mathrm{Z}$ dari model

1. Fix translasi arah sumbu $y=0$ (vertikal) pada 6 tumpuan roda.

Pada bidang simetri $\mathrm{X}-\mathrm{Y}$ dari model

1. Fix translasi sumbu $z=0$ (lateral) pada 3 titik pusat roda salah satu sisi saja (kanan).

2. Fix translasi sumbu $z=0$ (lateral) pada salah satu lateral stopper.

Pada bidang simetri $\mathrm{Y}-\mathrm{Z}$ dari model

1. Fix translasi sumbu $\mathrm{x}=0$ (longitudinal) pada titik tumpu primary spring. 
28 | Mustasyar Perkasa dkk., Optimalisasi Desain Struktur Bogie Las Light Rail Transit....,

\section{HASIL DAN PEMBAHASAN}

Dari hasil analisa menggunakan finite elemen method (FEM) terdapat dua alternatif penguatan pada bogie yaitu penguatan area kritis dengan penambahan pelat (backing plate) pada area bottom plate side frame dan penambahan sirip (web plate) pada area sisi dalam side frame.

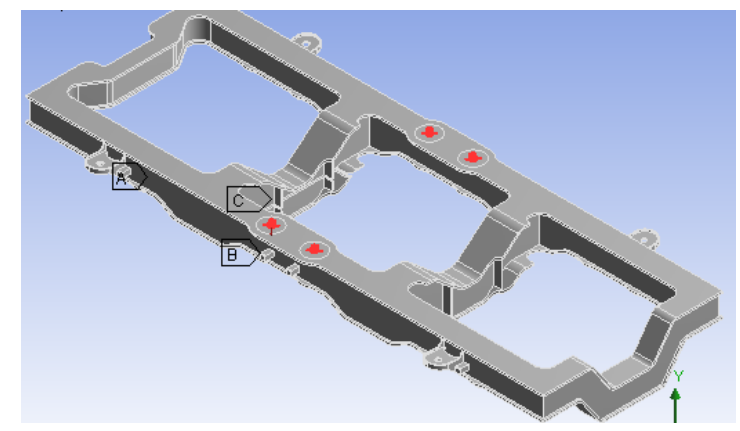

Gambar 2. Bogie las tanpa penguatan

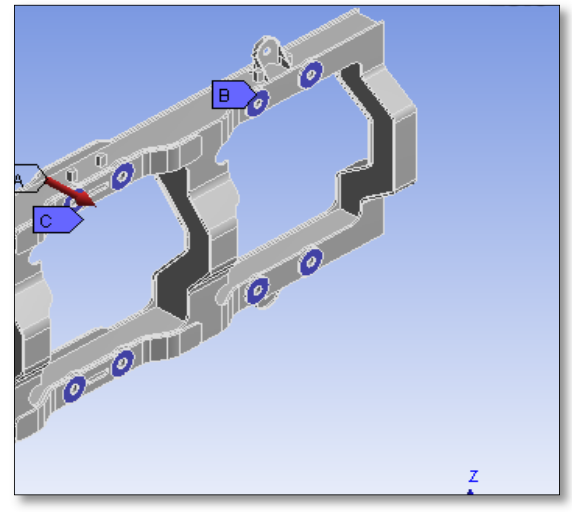

Gambar 3. Bogie las dengan penambahan backing plate

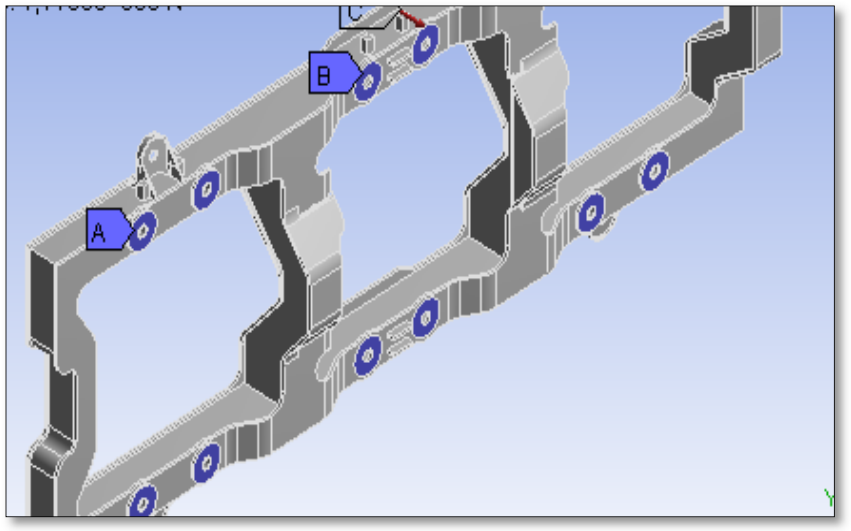

Gambar 4. Bogie las dengan penambahan sirip pelat 
Hasil simulasi numerik untuk penguatan dengan penambahan pelat di tunjukkan pada Tabel 2.

Tabel 2. Hasil simulasi numerik tanpa penguatan

\begin{tabular}{ccccc}
\multicolumn{5}{c}{ Tabel 2. Hasil simulasi numerik tanpa penguatan } \\
$\begin{array}{c}\text { Kasus } \\
\text { beban }\end{array}$ & $\begin{array}{c}\text { Tegangan } \\
\text { ijin maks } \\
(\mathrm{MPa})\end{array}$ & $\begin{array}{c}\text { Tegangan } \\
(\mathrm{MPa})\end{array}$ & $\begin{array}{c}\text { Desain awal } \\
\text { Defleksi } \\
\text { vertikal } \\
(\mathrm{mm})\end{array}$ & $\begin{array}{c}\text { Angka } \\
\text { keamanan }\end{array}$ \\
\hline 1 & 245 & 110,69 & 4,84 & 2,21 \\
2 & 245 & 155,27 & 18,15 & 1,58 \\
3 & 245 & 161,12 & 18,13 & 1,52 \\
4 & 245 & 187,57 & 27,46 & 1,31 \\
5 & 245 & 134,94 & 26,86 & 1,82 \\
6 & 245 & 186,22 & 27,52 & 1,32 \\
7 & 245 & 172,86 & 52,31 & 1,42 \\
\hline
\end{tabular}

Desain bogie tanpa penguat telah di uji dan di produksi. Pada Tabel 2 dapat di jelaskan bahwa tegangan terbesar terjadi pada kasus pembebanan 4 yaitu sebesar 187,57 MPa dengan defleksi yang terjadi sebesar 27,46 $\mathrm{mm}$. Hasil ini menunjukkan bahwa secara simulasi software tegangan yang terjadi masih di bawah tegangan yieldnya sebesar $245 \mathrm{MPa}\left(245 \mathrm{~N} / \mathrm{mm}^{2}\right)$. Berdasarkan uji statis, pada kasus beban 4, 6 dan 7 terjadi tegangan yang mendekati tegangan yieldnya yaitu sebesar 225,75 MPa pada kasus beban 4, 236,25 MPa pada kasus beban 6, dan $217,56 \mathrm{MPa}$ pada kasus beban 7. Kondisi tersebut terjadi pada bagian side frame bogie. Tegangan sebesar itu dapat menyebabkan kegagalan struktur pada bogie.

Desain dengan penambahan pelat (backing plate) didapat bahwa tegangan terbesar terjadi pada kasus pembebanan 4 yaitu sebesar 187,56 Mpa, dan defleksi yang terjadi sebesar 27,45 mm. Hasil ini menunjukkan tegangan yang terjadi secara simulasi numerik masih di bawah tegangan ijin material walaupun terjadi penurunan tegangan. Untuk hasil aktual tegangan yang terjadi belum di ketahui karena belum di lakukan pengujian secara experimental.

Tabel 3. Hasil simulasi numerik penguatan dengan penambahan pelat

\begin{tabular}{ccccc}
\hline Kasus & $\begin{array}{c}\text { Tegangan } \\
\text { ijin maks } \\
(\mathrm{MPa})\end{array}$ & $\begin{array}{c}\text { Tegangan } \\
(\mathrm{MPa})\end{array}$ & $\begin{array}{c}\text { Desain awal } \\
\text { Defleksi } \\
\text { vertikal } \\
(\mathrm{mm})\end{array}$ & $\begin{array}{c}\text { Angka } \\
\text { keamanan }\end{array}$ \\
\hline 1 & 245 & 110,69 & 4,71 & 2,28 \\
2 & 245 & 153,63 & 18,64 & 1,59 \\
3 & 245 & 159,81 & 18,08 & 1,53 \\
4 & 245 & 187,56 & 27,45 & 1,31 \\
5 & 245 & 133,85 & 26,83 & 1,83 \\
6 & 245 & 186,23 & 27,51 & 1,32 \\
7 & 245 & 172,90 & 52,28 & 1,42 \\
\hline
\end{tabular}

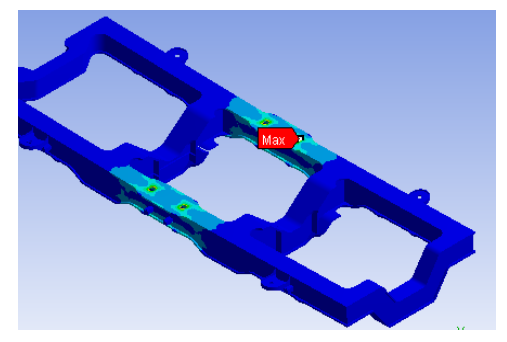

Gambar 5. Posisi tegangan maksimum pada struktur bogie tanpa penguat

Desain dengan penambahan sirip pelat pada lokasi yang terjadi tegangan krtis berdasarkan hasil pengujian expearimental didapatkan tegangan terbesar terjadi pada kasus pembebanan 4, yaitu sebesar 187,64 MPa dengan defleksi sebesar 27,46 mm. Hasil ini menunjukkan bahwa tegangan yang tterjadi secara perhitungan numerik masih di bawah tegangan ijin material. Pada kasus desain dengan penambahan sirip pelat dapat di ketahui bahwa sebagian kasus pembebanan mengalami penurunan tegangan. 
30 | Mustasyar Perkasa dkk., Optimalisasi Desain Struktur Bogie Las Light Rail Transit....,

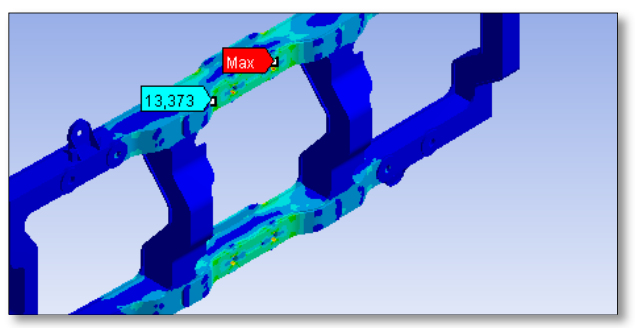

Gambar 6. Posisi tegangan maksimum pada bogie dengan penambahan backing plate

Tabel 4. Hasil simulasi numerik penguatan dengan penambahan sirip pelat

\begin{tabular}{ccccc}
\hline Kasus & $\begin{array}{c}\text { Tegangan } \\
\text { ijin maks } \\
(\mathrm{MPa})\end{array}$ & $\begin{array}{c}\text { Tegangan } \\
(\mathrm{MPa})\end{array}$ & $\begin{array}{c}\text { Desain awal } \\
\text { Defleksi } \\
\text { vertikal } \\
(\mathrm{mm})\end{array}$ & $\begin{array}{c}\text { Angka } \\
\text { Keamanan }\end{array}$ \\
\hline 1 & 245 & 96,24 & 4,57 & 2,55 \\
2 & 245 & 145,69 & 17,85 & 1,68 \\
3 & 245 & 153,66 & 17,85 & 1,59 \\
4 & 245 & 187,64 & 27,46 & 1,31 \\
5 & 245 & 117,80 & 26,75 & 2,08 \\
6 & 245 & 186,43 & 27,50 & 1,31 \\
7 & 245 & 171,34 & 53,19 & 1,43 \\
\hline
\end{tabular}

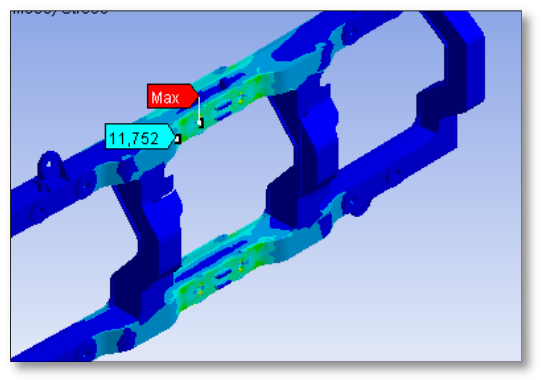

Gambar 7. Posisi tegangan maksimum pada bogie dengan penambahan sirip pelat

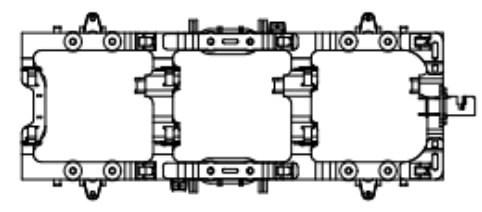

BOTTOM VIEW
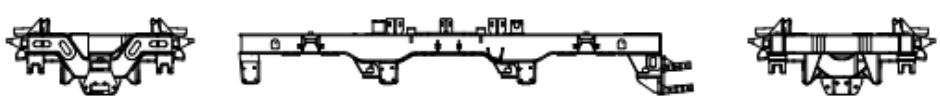

RIGHT VIEW

FRONT VIEW

LEFT VIEW

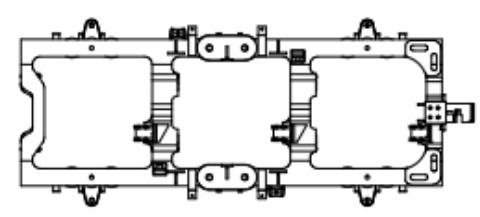

Gambar 8. Gambar penampang bogie las LRT 


\section{KESIMPULAN}

Hasil analisa numerik pada bogie las tanpa penguatan di dapatkan nilai keamanan tertinggi pada kasus beban 1 dengan nilai tegangan 110,69 MPa, defleksi vertikal sebesar 4,84 mm dan angka keamanan 2,21. Pada bogie las dengan penguatan pelat angka keamanan juga terdapat pada kasus beban 1 dengan nilai tegangan 110,69 MPa, defleksi vertikal 4,71 $\mathrm{mm}$ dan angka keamanan 2,28. Pada bogie las dengan penambahan sirip pelat angka keamanan berada pada kasus beban 1 dengan nilai tegangan 96,24 $\mathrm{MPa}$, defleksi vertikal 4,57 dan angka keamanan 2,55. Hasil pengujian diatas dapat disimpulkan bahwa penguatan bogie frame dengan penambahan backing plate pada bottom plate dan penambahan sirip masih aman untuk di gunakan. Tegangan maksimum yang terjadi pada kedua metode mendekati nilai yang sama pada kasus pembebanan 4, namun pada kasus pembebanan lainnya tegangan maksimum menurun. Secara umum metode penguatan dengan penambahan sirip hasilnya lebih baik dari pada penambahan backing plate dan desain awal.

\section{DAFTAR PUSTAKA}

[1] Tyrell, D.C.J.P.o.t.I.o.M.E. 2002 Part F: Journal of Rail and R. Transit, US rail equipment crashworthiness standards 216(2) 123

[2] Perhubungan K PM No 13 Tahun 2011 Standar, Tata Cara Pengujian dan Sertifikasi Kelaikan Kereta dengan Penggerak Sendiri

[3] Railways I U o 1993 Passenger Rolling Stock, Bogie Frame Structure Strength Tests

[4] Ihlas A J J T B d B T 2019 Analisis Kerusakan Rel Kereta Api Angkutan Batubara 7(1) 7

[5] Perhubungan, K., PM No 15 Tahun 2011, Standar, Tata Cara Pengujian Dan Sertifikasi Kelaikan Kereta Yang ditarik Lokomotif

[6] Khurmi R dan Gupta J K 1982 A Text Book Of Machine Design Eurasia Publishing House, Ram Nagar, New Delhi

[7] Zakaria Y J U S B Analyzing a bogie frame behavior by using the experimental method and Ansys simulations 149

[8] Preumont A 2018 Vibration control of active structures an introduction 246 Springer

[9] Juvinall R C 2007 Fundamentals of machine component design 